\title{
SNRPD1 confers diagnostic and therapeutic values on breast cancers through cell cycle regulation
}

Xiaofeng Dai ${ }^{{ }^{*+}} \mathbb{B},{\text { Lihui } Y u^{1+}, \text { Xiao } \text { Chen }^{2} \text { and Jianying Zhang }}^{3}$

\begin{abstract}
Background: SNRPD1 is a spliceosome-associated protein and has previously been implicated with important roles in cancer development.

Methods: Through analyzing the differential expression patterns and clinical association of splicing associated genes among tumor and tumor adjacent samples across different tumors and among different breast cancer subtypes, we identify the tumor promotive role of SNRPD1 using multiple publicly available datasets. Through pathway, gene ontology enrichment analysis and network construction, we linked the onco-therapeutic role of SNRPD1 with cell cycle. Via a series of experimental studies including knockdown assay, QPCR, western blotting, cell cycle, drug response assay, we confirmed the higher expression of SNPRD1 at both gene and protein expression levels in triple negative breast cancer cells, as well as its roles in promoting cell cycle and chemotherapy response.
\end{abstract}

Results: Our study revealed that SNRPD1 over-expression was significantly associated with genes involved in cell cycle, cell mitosis and chromatin replication, and silencing SNRPD1 in breast cancer cells could lead to halted tumor cell growth and cell cycle arrest at the $G_{0} / G_{1}$ stage. We also found that triple negative breast cancer cells with reduced SNRPD1 expression lost certain sensitivity to doxorubicin whereas luminal cancer cells did not.

Conclusions: Our results suggested the prognostic value of SNRPD1 on breast cancer survival, its potential as the therapeutic target halting cell cycle progression for breast cancer control, and warranted special attention on the combined use of doxorubicin and drugs targeting SNRPD1.

Keywords: SNRPD1, Breast cancer, Cell cycle arrest, Prognosis, Therapeutics

\section{Introduction}

Spliceosome is a dynamic complex that catalyzes the splicing of precursor RNA into mRNA in eukaryotic cells and comprised of 5 small nuclear ribonucleoproteins (snRNPs), i.e., U1, U2, U4, U5, U6, and more than 200 polypeptides $[1,2]$. Most spliceosomal snRNPs contain a common set of core $\mathrm{Sm}$ proteins, i.e., SNRPB, SNRPD1, SNRPD2, SNRPD3, SNRPE, SNRPF, SNRPG

\footnotetext{
*Correspondence: xiaofeng.dai@jiangnan.edu.cn

${ }^{\dagger}$ Xiaofeng Dai and Lihui Yu contributed equally to this work.

${ }^{1}$ Wuxi School of Medicine, Jiangnan University, Wuxi, Jiangsu, China

Full list of author information is available at the end of the article
}

[2]. It is widely acknowledged that accurate splicing is essential to ensure normal cell functionalities such as cell cycle, apoptosis, migration and invasion [3-8]. It was observed that altered expression of genes involved in the splicing machinery was correlated with the incidence of hematological diseases such as chronic lymphocytic leukemia and myelodysplasia [9-12]. We analyzed the transcriptomic profiles of the 7 core $\mathrm{Sm}$ proteins across 31 cancer types and among breast cancer subtypes, and found that SNRPD1 had the highest number of cancers with over 2 folds up-regulation between cancer and normal tissues (Table 1), and the distribution of SNPRD1 could be nicely split into two

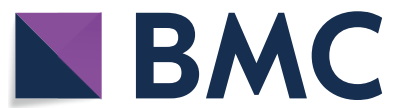

(c) The Author(s) 2021. This article is licensed under a Creative Commons Attribution 4.0 International License, which permits use, sharing, adaptation, distribution and reproduction in any medium or format, as long as you give appropriate credit to the original author(s) and the source, provide a link to the Creative Commons licence, and indicate if changes were made. The images or other third party material in this article are included in the article's Creative Commons licence, unless indicated otherwise in a credit line to the material. If material is not included in the article's Creative Commons licence and your intended use is not permitted by statutory regulation or exceeds the permitted use, you will need to obtain permission directly from the copyright holder. To view a copy of this licence, visit http://creativeco mmons.org/licenses/by/4.0/. The Creative Commons Public Domain Dedication waiver (http://creativecommons.org/publicdomain/ zero/1.0/) applies to the data made available in this article, unless otherwise stated in a credit line to the data. 
Table $1 \mathrm{Log}_{2}$ fold change of gene expression between tumor and adjacent normal tissues across 31 cancer types using transcriptomic data stored in TCGA

\begin{tabular}{|c|c|c|c|c|c|c|c|}
\hline & SNRPD1 & SNRPB & SNRPE & SNRPF & SNRPG & SNRPD3 & SNRPD2 \\
\hline ACC & 0.85 & 1.21 & 0.41 & 1.11 & 0.04 & 0.19 & 0.90 \\
\hline BLCA & 1.25 & 1.44 & 0.92 & 1.33 & 1.15 & 0.79 & 1.03 \\
\hline BRCA & 1.22 & 0.90 & 1.19 & 0.91 & 0.90 & 1.04 & 0.61 \\
\hline CESC & 2.07 & 1.48 & 0.73 & 1.61 & 1.95 & 1.25 & 0.67 \\
\hline $\mathrm{CHOL}$ & 2.44 & 2.40 & 2.34 & 1.29 & 1.40 & 1.31 & 2.18 \\
\hline COAD & 1.77 & 1.77 & 1.34 & 1.63 & 1.27 & 1.04 & 1.18 \\
\hline DLBC & 6.42 & 3.05 & 5.55 & 4.74 & 5.48 & 3.82 & 5.04 \\
\hline ESCA & 1.34 & 1.10 & 1.07 & 0.98 & 0.92 & 0.33 & 0.38 \\
\hline GBM & 1.58 & 2.12 & 1.78 & 1.64 & 2.78 & 1.77 & 1.44 \\
\hline HNSC & 0.97 & 0.99 & 0.89 & 0.77 & 0.85 & 0.74 & 0.75 \\
\hline $\mathrm{KICH}$ & -0.01 & 0.53 & -0.82 & 0.07 & -1.00 & -0.36 & 0.13 \\
\hline KIRC & 0.56 & 0.36 & 0.46 & 0.34 & 0.04 & 0.02 & 0.47 \\
\hline KIRP & 0.64 & 0.93 & 0.44 & 0.85 & 0.45 & 0.10 & 0.64 \\
\hline LAML & -1.99 & -1.26 & -1.41 & -1.72 & -2.76 & -1.05 & -2.10 \\
\hline LGG & 1.38 & 1.19 & 1.39 & 1.28 & 1.62 & 1.53 & 0.38 \\
\hline LIHC & 1.52 & 1.82 & 1.84 & 1.08 & 0.98 & 1.10 & 1.46 \\
\hline LUAD & 1.12 & 0.65 & 1.21 & 0.62 & 0.79 & 0.39 & 0.64 \\
\hline LUSC & 1.83 & 1.37 & 1.51 & 1.21 & 1.44 & 1.09 & 1.22 \\
\hline ov & 1.15 & 1.49 & 0.44 & 0.86 & 1.07 & 0.21 & 0.18 \\
\hline PAAD & 2.91 & 2.47 & 1.73 & 2.19 & 2.23 & 2.36 & 2.06 \\
\hline PCPG & 0.32 & -0.16 & -0.22 & 0.32 & -0.44 & -0.25 & 0.17 \\
\hline PRAD & 0.71 & 0.55 & 0.53 & 0.77 & 0.42 & 0.75 & 0.45 \\
\hline READ & 1.62 & 1.84 & 1.42 & 1.72 & 1.46 & 1.05 & 1.14 \\
\hline SARC & 1.31 & 0.90 & 0.55 & 0.94 & 0.55 & 0.66 & 0.53 \\
\hline SKCM & 1.38 & 0.86 & 1.34 & 0.73 & 1.25 & 0.91 & 0.78 \\
\hline STAD & 2.12 & 1.74 & 1.28 & 1.77 & 1.53 & 1.13 & 0.90 \\
\hline TGCT & 1.30 & 1.83 & 2.03 & 1.85 & 1.18 & 1.85 & 1.15 \\
\hline THCA & 0.65 & 0.46 & 0.26 & 0.18 & 0.24 & 0.48 & 0.49 \\
\hline THYM & 6.11 & 2.73 & 5.66 & 4.90 & 5.08 & 3.94 & 4.57 \\
\hline UCEC & 1.84 & 1.06 & 1.30 & 1.57 & 1.48 & 1.00 & 1.05 \\
\hline UCS & 2.00 & 1.40 & 1.66 & 1.39 & 1.39 & 0.89 & 1.35 \\
\hline
\end{tabular}

No. of cancers

\begin{tabular}{rlllllll}
$\begin{array}{c}\text { upregulated } \\
>2 \text { Fold }\end{array}$ & 22 & 19 & 18 & 17 & 17 & 14 \\
\hline
\end{tabular}

sub-distributions by TNBC and non-TNBC while the other genes did not (Fig. 1a). In addition, spliceosome assembly components were revealed as the most enriched pathway deregulated in breast cancers with SNRPD1 being an important player according to exonic expression profiling of 120 breast tumors and 45 benign lesions [13]. A recent reprint identified SNRPD1 as one of the top 10 essential ribosome binding proteins for breast cancer survival from both the genome-scale RNAi loss-of-function screens (DEMETER2) and the genome-scale CRISPR-Cas9 loss-of-function screens (CERES) [14]. SNRPD1 over-expression was used to define subsets of highly aggressive cancers [15] and was proposed as therapeutic targets of multiple cancers such as melanoma, lung and breast tumor cells as a result of induced autophagy [15].

We therefore decided to focus on SNRPD1 and explore its potential diagnostic and therapeutic values in breast cancers.

Through computational predictions followed by experimental validations, we identified from this study that SNRPD1 over-expression is prognostic of high malignancies among breast cancer patients due to accelerated cell cycle, and proposed that targeting 


\section{a \\ SNRPG \\ SNRPF \\ SNRPE \\ SNRPB \\ SNRPD3 \\ SNRPD2 \\ SNRPD1}

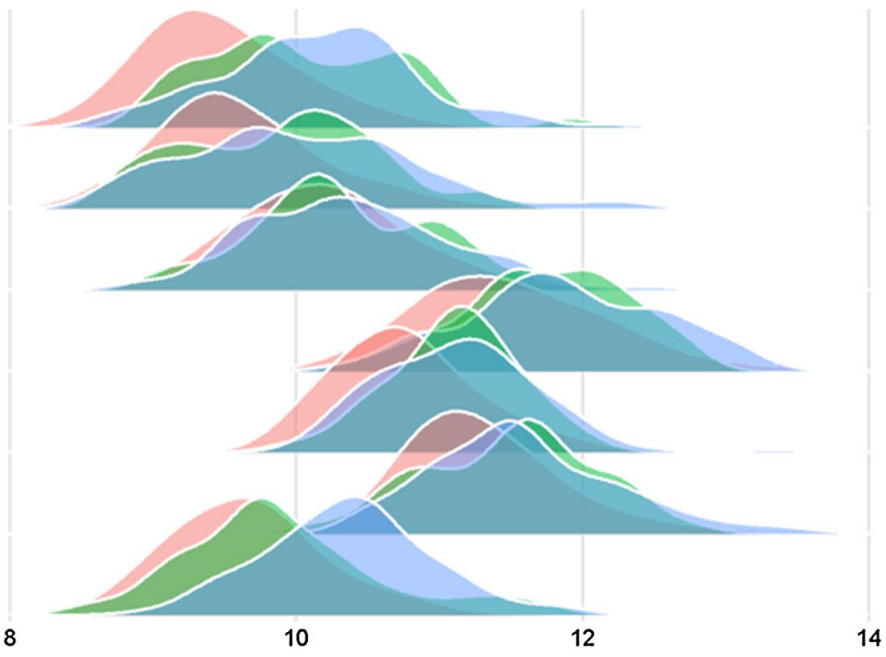

subtype

Luminal

HER2p

TNBC

Gene expression

b
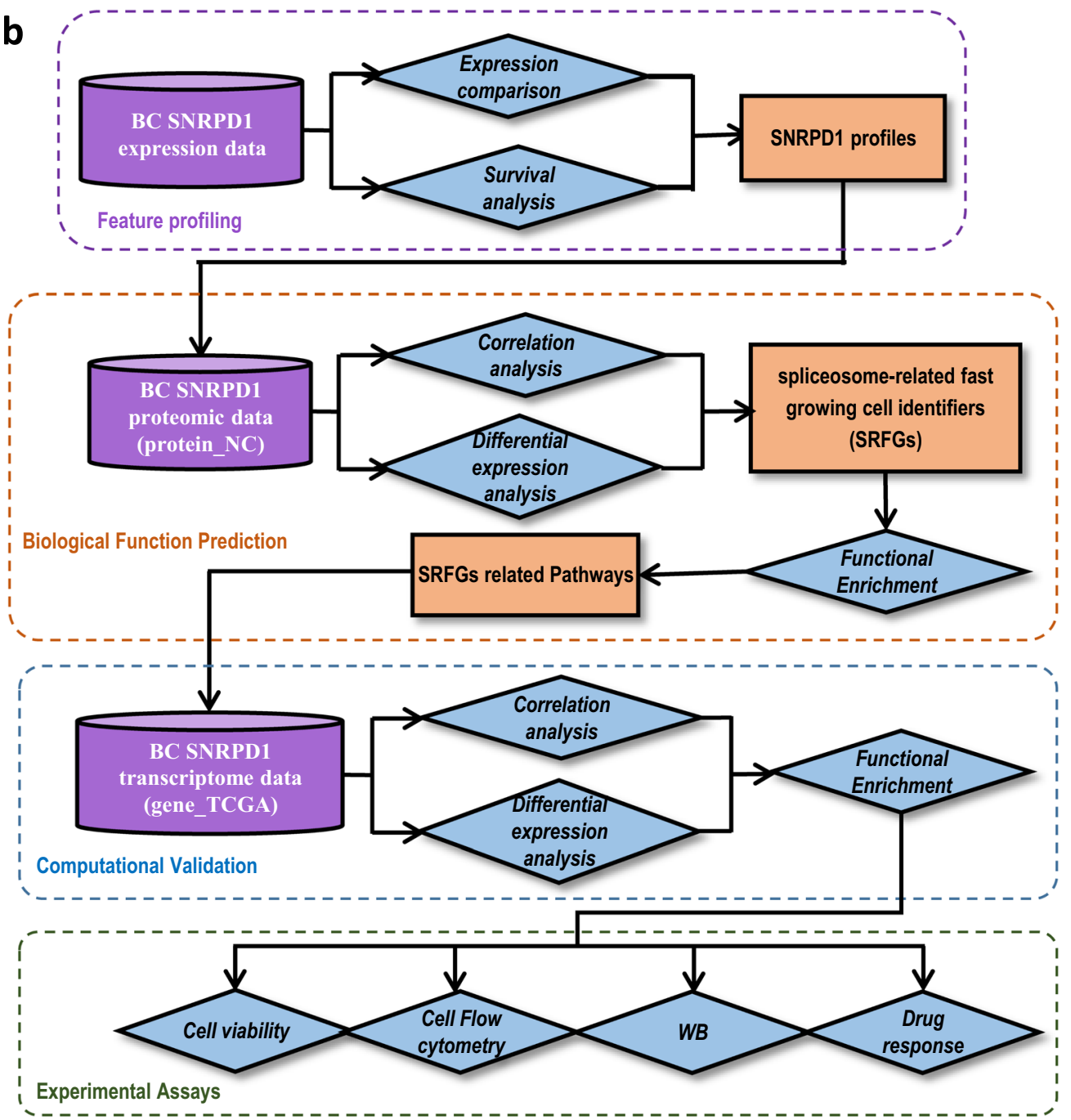

Fig. 1 Rational and workflow of this study. a Distribution of the gene expression of spliceosomal core Sm proteins across breast cancer subtypes using TCGA transcriptomic data (gene_TCGA). b Study workflow 
SNRPD1 could halt cell cycle progression at the $\mathrm{G}_{0} / \mathrm{G}_{1}$ phase for effective breast cancer management.

\section{Materials and methods Computational analysis Data}

The breast cancer quantitative proteomic data set, which is comprised of 9995 proteins and 45 samples, was downloaded from https://www.nature.com/articles/s41467019-09018-y [16], namely the 'Protein_ NC' dataset.

TCGA breast cancer transcriptomic data together with the clinical data were retrieved from TCGA [17] data portal (http://cancergenome.nih.gov) on Date April 1st 2018. Files containing patients' transcriptome data were combined into a single matrix comprised of 20,531 genes and 931 patients including 84 death events. The maximum follow-up time on overall survival (OS) is 120 months. This dataset contains 110 TNBC patients, 36 HER2 positive patients, and 785 luminal patients. The mRNA data was $\log 2$ transformed before data processing. This data was referred to as the 'gene_TCGA' dataset in this study.

Gene expression data of splicosome core proteins across 31 cancers were retrieved from GEPIA2 [18], which holds RNA sequencing data of 9736 tumors and 8587 normal samples from the TCGA and the GTEx (Genotype-Tisuse Expression) projects.

Breast cancer cell line microarray data consisting of 183 primary breast tumor samples was downloaded from https://www.ebi.ac.uk/arrayexpress/experiments/EMTAB-181/ [19, 20]. The data was quantile-normalized followed by $\log 2$ transformation, and referred to as the 'gene_CLM' dataset in this study.

The web interface tool named 'GEPIA' was used to retrieve TCGA mRNA expression data of input genes across all cancer types [18].

\section{Survival analysis}

The 10-year breast cancer OS analysis and relapse free survival (RFS) analysis of SNRPD1 were performed using Kaplan Meier plotter [21] (http://kmplot.com/analysis/). A p-value $<0.05$ from the log rank test was used as the threshold to assess the test statistical significance.

\section{Enrichment analysis}

Gene Ontology (GO) [22] and Kyoto Encyclopedia of Genes and Genomes database (KEGG) [23] enrichment analysis were performed using the $\mathrm{R}$ package 'clusterProfiler' and 'org.Hs.db.eg' [24]. Fisher's exact test was utilized to measure the significance of GO terms and biological pathways. The p-values were adjusted using Benjamini-Hochberg false discovery rate (FDR), and $p<0.01$ was considered as the significance threshold [25]. Gene
Set Enrichment Analysis (GSEA) was performed to test each functional biological term.

\section{Hierarchical clustering}

Samples and genes were clustered in a form of heatmap using the 'pheatmap' function, which uses the hierarchical clustering function 'hclust' with 'distance' as the correlation and 'ward.D2' as the clustering method. Patient subtype was annotated using different colors on the top of the heatmap.

\section{Correlation analysis}

Pearson correlation was calculated using the 'gene TCGA' dataset to evaluate the correlations of SNRPD1 with Ki67, ER, and HER2. The calculation was performed in R using function 'corr.'

\section{Correlation analysis}

Receiver operating characteristic (ROC) curves were calculated using the $\mathrm{R}$ package 'ROCR' to compare the performances of SNRPD1 and KI67 in prognosing triple negative breast cancers.

\section{Experiments \\ Cell culture}

The luminal cell line MCF7 and TNBC cell line MDAMB231 were used. Both cells were stored in liquid nitrogen in $90 \% \mathrm{FBS}$ and $10 \%$ DMSO solution, thawed in DMEM medium supplemented with $10 \%$ fetal bovine serum (Gibco), and cultured at $37^{\circ} \mathrm{C}$ with $5 \% \mathrm{CO}_{2}$.

\section{siRNA design}

Two siRNAs targeting SNRPD1 were synthesized by company GenePharma (Additional file 1: Table S1) and pooled together on usage. GenePharma Silencer Select Negative Control was used as the negative control.

\section{Q-PCR}

Total RNA was extracted using TRIzol reagent (TianGen) $24 \mathrm{~h}$ after siRNA transfection, following reverse transcription into cDNA using PrimeScriptRT reverse transcriptase (Takara). Primers for Q-PCR were listed in Additional file 1: Table S2. The qPCR experiments were conducted using the qPCR kit (CWbio) following the manufacture's protocol and using the Roche LightCycler 480 qPCR system. The relative expression levels were calculated using the $2^{-\triangle \Delta \mathrm{Ct}}$ methods. Student $\mathrm{T}$ test was used to evaluate the statistical significance with $\mathrm{p}$ value $<0.05$ being considered statistically significant. Primers designed for qPCR were listed in Additional file 1: Table S2. 


\section{Western blot}

Total protein was extracted $48 \mathrm{~h}$ after transfection using RIPA lysis buffer supplemented with protease inhibitors. The protein concentration was estimated using the BCA Protein Assay Kit (Tiangen) following the standard protocol. Protein samples were separated on SDS polyacrylamide gel and transferred to polyvinylidene difluoride (PVDF) membranes using BioRad wet transfer apparatus. The membrane was incubated with primary antibodies overnight at $4{ }^{\circ} \mathrm{C}$ and with secondary antibodies for $2 \mathrm{~h}$ after being blocked in 5\% non-fat milk for $1 \mathrm{~h}$ at the room temperature. The signal was detected using Tanon HighsigECL western Blotting substrate reagents and BioRad imaging apparatus.

\section{Proliferation assay}

Cells were prepared in 96-well plates with $\sim 50 \%$ confluency before transfection. The siRNAs and lipo3000 reagents were mixed in Opti-MEM medium for 15-20 min before transfection with a final siRNA concentration being $20 \mathrm{nl}$ per well. Cell proliferation was measured using CKK-8 (Dojindo) $48 \mathrm{~h}$ after transfection, and luminescence was detected using EZ Read 800 microplate Reader (Biochrom) after incubation at $37^{\circ} \mathrm{C}$ for $2 \mathrm{~h}$. Student $\mathrm{T}$ test was performed using $\mathrm{R}$ to evaluate cell viability reduction with $\mathrm{p}$ value $<0.05$ being considered statistically significant.

\section{Cell flow cytometry}

Cell flow cytometry was performed $48 \mathrm{~h}$ after siRNA transfection. Cells were collected using EDTA-free trypsin, washed twice using $0.5 \mathrm{ml} \mathrm{PBS}$, suspended in cold $70 \%$ ethanol, and stored in $4{ }^{\circ} \mathrm{C}$ overnight. Ethanol was removed and cells were re-suspended in PBS the next day followed by $0.05 \mathrm{mg} / \mathrm{ml}$ Propidium Iodide (PI) addition. Cells were kept in darkness on ice for $30 \mathrm{~min}$ before being sent to BD C6 flow cytometry. Analysis was performed using the flowjo software.

\section{Doxorubicin resistance assays}

Various concentrations of doxorubicin (1 nM, $10 \mathrm{nM}$, $100 \mathrm{nM}, 1000 \mathrm{nM}, 10,000 \mathrm{nM}$ ) with 3 replicates were used for both control and SNRPD1 knocked down celllines. Doxorubicin (Sigma) was added $24 \mathrm{~h}$ after siRNA transfection. 10ul per well of CKK-8 regent was added $96 \mathrm{~h}$ after transfection, and luminescence was detected using EZ Read 800 microplate Reader after cell incubation at $37^{\circ} \mathrm{C}$ for $2 \mathrm{~h}$. The dose-response curve and halfmaximum inhibitory concentration (IC50) values were obtained using the 'drc' package [26] in R, where a four parameter log-logistic model (LL.4) was used for data fitting. Statistical significance on IC50 alteration was evaluated by student $\mathrm{T}$ test.
The workflow of this study was presented as Fig. 1b.

\section{Results \\ Bioinformatics analysis predicts the association of SNPRD1 with cell cycle}

SNRPD1 expression is higher in malignant or highly proliferative cells than normal cells in all types of cancers except for LAML (Acute Myeloid Leukemia) according to TCGA mRNA data (Fig. 2a). Triple negative breast cancers (TNBCs) are more malignant and grow faster than the other breast cancer subtypes [27], which exhibited higher SNRPD1 expression than non-TNBCs in TCGA patient transcriptomic data $(\mathrm{p}=8.4 \mathrm{E}-4$, Fig. $2 \mathrm{~b})$ and patient protein data protein_NC ( $p=0.0016$, Fig. $2 d)$. Basal breast cancer cells are the counterpart of TNBCs at the cell line level, which showed higher SNRPD1 expression than non-basal cells according to the CLM cell line gene expression data $(\mathrm{p}<2 \mathrm{E}-16$, Fig. 2c). Both $\mathrm{OS}$ and RFS analyses showed that high SNRPD1 expression was prognostic of unfavourable clinical outcome with statistical significance $(H R=1.49, p=0.0021$ for $O S, H R=1.52$, $\mathrm{p}=1.6 \mathrm{E}-13$ for RFS, Fig. 2e, f). ROC curves showed the performances of SNRPD1 and KI67 in prognosing triple negative breast cancers $(\mathrm{AUC}=0.82$ for SNRPD1, $\mathrm{AUC}=0.8$ for KI67, Fig. 2g).

We defined genes differentially expressed between TNBC and non-TNBC cells and highly correlated with SNRPD1 expression as 'spliceosome-related fast-growing cell identifiers' (SRFGs) and identified 434 SRFGs from the proteomic data (Additional file 1: Table S3).

GO and KEGG pathway enrichment analyses showed that SRFGs were enriched in 'cell cycle', 'DNA replication' and 'mitosis' using both the 'protein_NC' proteomic (Fig. 3a, b) and 'gene_TCGA' transcriptomic data (Fig. 3c, d). It was shown that 'DNA transcription', 'DNA repair' and 'Cell cycle' were the most significantly enriched GO terms besides 'splicing'. A network depicting the relationship between the enriched GO terms was constructed using SRFGs from the protein_NC data, where each node represents an enriched GO term and nodes with similarities $>0.3$ were connected by edges. The nodes in the GO term network were categorized according to their general functionalities, where 'RNA processing' and 'cell cycle' were popped up as two major clusters. The 'cell cycle' cluster was primarily comprised of 5 inter-connected sub-clusters (Fig. 3e).

In order to confirm the role of cell cycle in breast cancer development, unsupervised hierarchical clustering of protein and mRNA data was performed. TNBC patients were clustered together using cell cycle genes from SRFGs as the classifier using both the proteomic data (Fig. 4a) and the transcriptomic data (Fig. 4c), suggestive of the important role of cell cycle in differentiating 


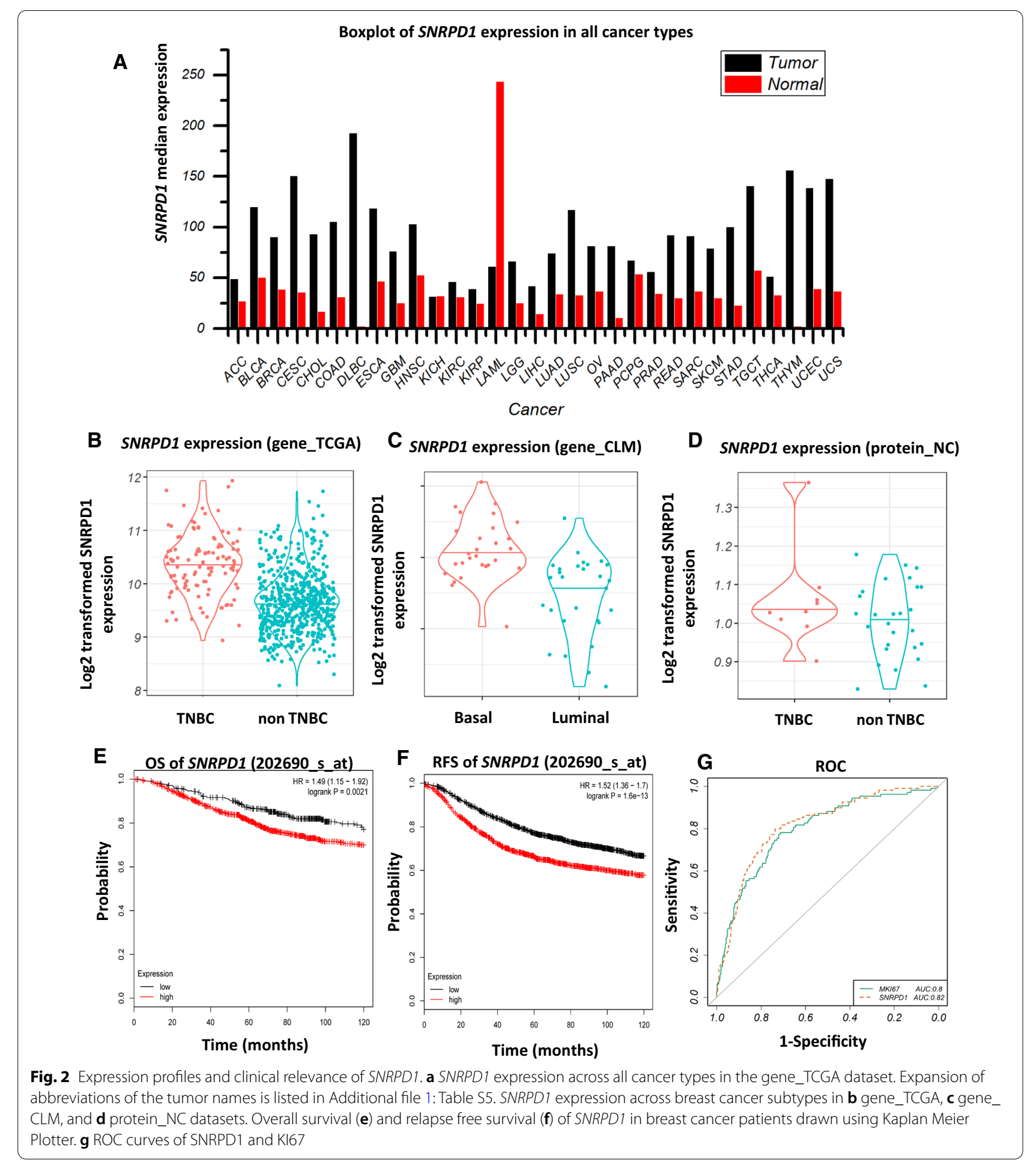

TNBC and non-TNBC patients (Fig. 4a, c). GSEA further confirmed the enrichment of cell cycle related genes in SRFGs using both protein_NC and gene_TCGA datasets (Fig. 4b, d).
Correlation analysis showed that SNPRD1 expression was highly correlated with cell cycle, with the correlation scores being $0.44,0.25$ and 0.35 , respectively, in the protein_NC, gene_TCGA and gene_CLM datasets. 


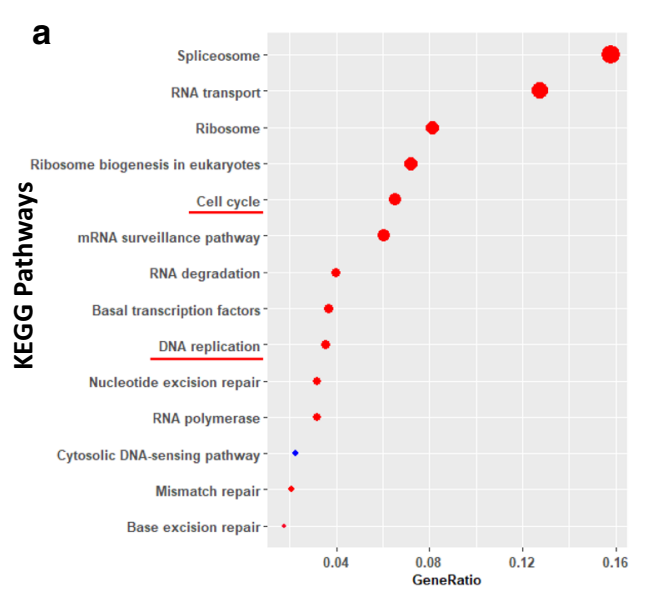

C

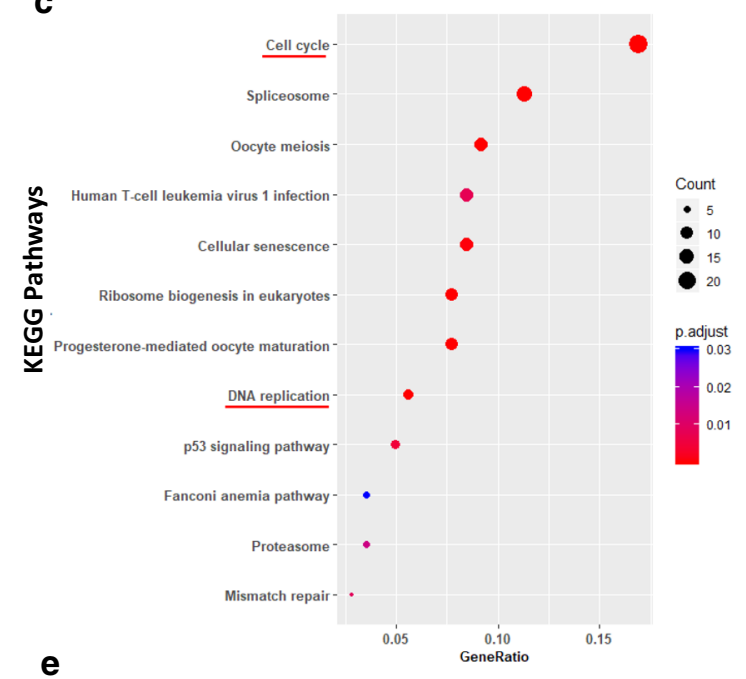

b

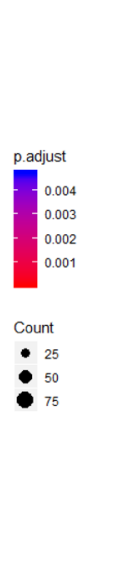

d

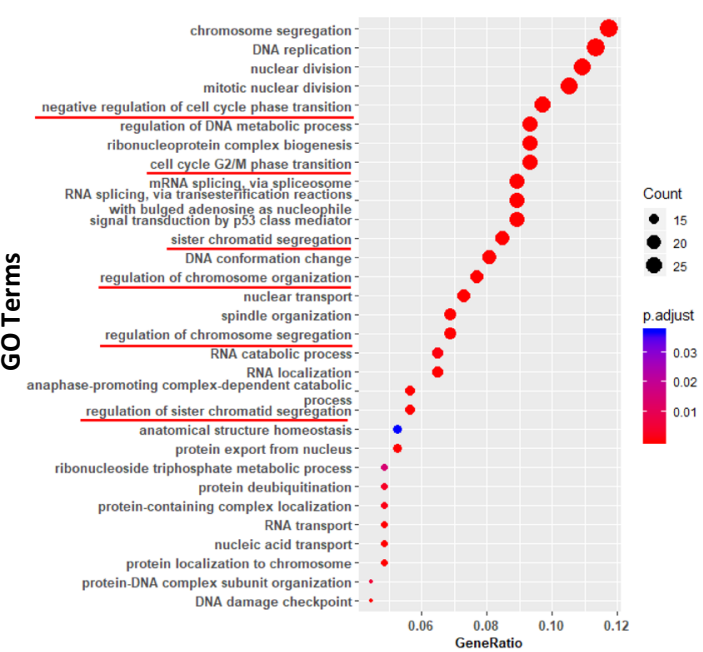

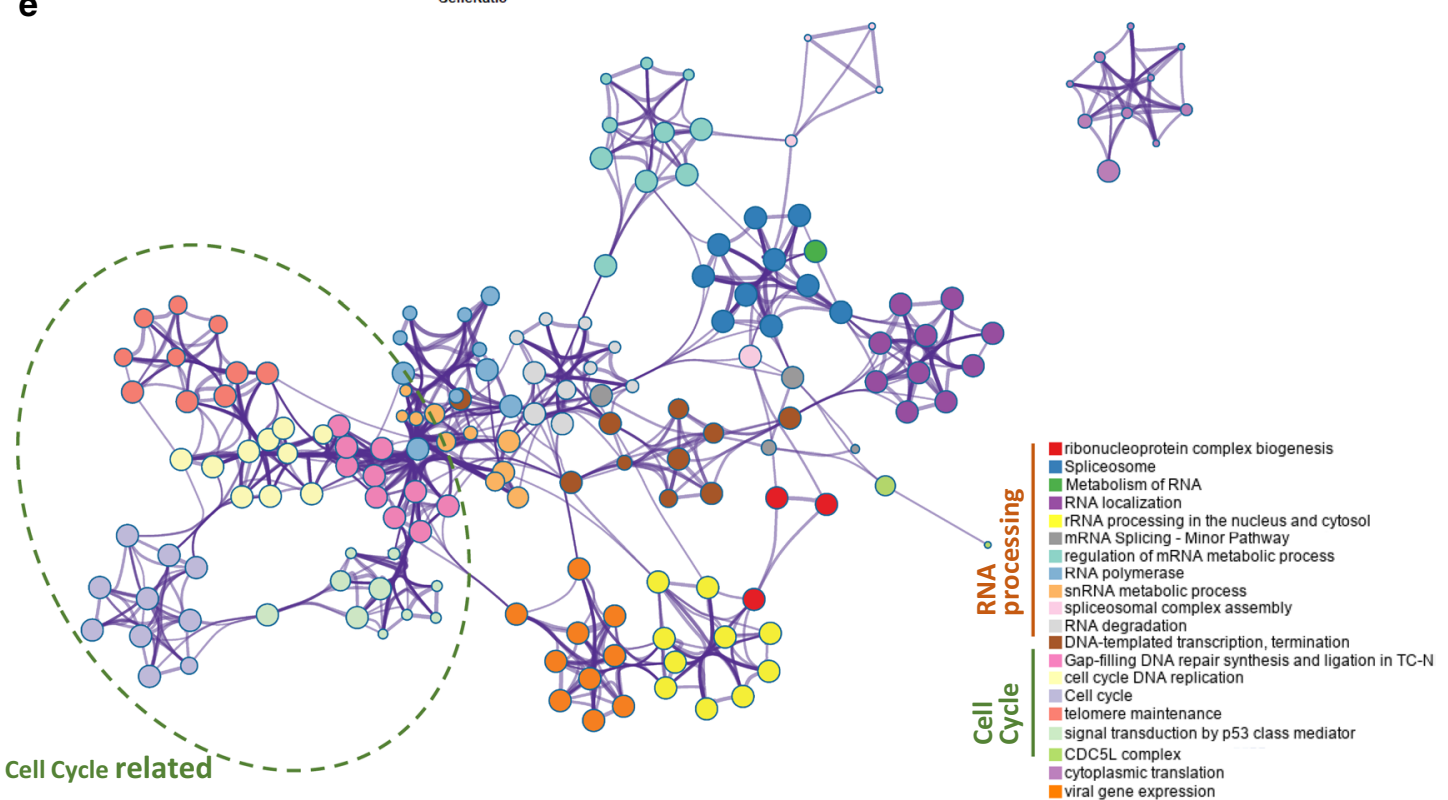

Fig. 3 Functional enrichment of SRFGs. a KEGG and $\mathbf{b}$ GO enrichment of SRFGs using the protein_NC dataset. $\mathbf{c}$ KEGG and $\mathbf{d}$ GO enrichment of SRFGs using the gene_TCGA dataset. e Network of enriched GO terms constructed using protein_NC data 
Experimental validation confirms the role of SNRPD1 in cell cycle control

Two siRNAs were designed (Fig. 5a) and purchased (Additional file 1: Table S1). E value was used to assess the significance of the homologous similarity of two sequences, where two sequences with $\mathrm{E}<10 \mathrm{E}-5$ were considered highly homologous and such a homology was nearly confirmed without a need of further validation if $\mathrm{E}<10 \mathrm{E}-6$. The siRNA-1 could target the NM_006938.4 transcript and the siRNA-2 could target both the NM_006938.4 and the NM_001291916.2 transcripts. None of these two siRNAs could target cell cycle related siRNAs assessed in this study with statistically significant E value (Table 2).

Both siRNAs could significantly silence SNRPD1 $(\mathrm{p}=0.002$ for siRNA-1 and $\mathrm{p}=8.6 \mathrm{E}-4$ for siRNA2 in MCF7; $\mathrm{p}=0.0091$ for $\mathrm{siRNA}-1$ and $\mathrm{p}=0.0093$ for siRNA2 in MDAMB231), and we obtained considerably improved inhibitory effects on SNRPD1 expression by pooling these two siRNAs together $(\mathrm{p}=1.22 \mathrm{E}-5$ in MCF7, $\mathrm{p}=1.64 \mathrm{E}-5$ in MDAMB231, Fig. 5b). Similarly, SNRPD1 was effectively knocked down in MCF7 and MDAMB231 cells at the protein expression level (Fig. 5c). We therefore used pooled siRNAs in the following assays. In particular, SNRPD1 mRNA expression was reduced to less than $10-25 \%$ of that of the control cells at the gene expression level (Fig. 5b), and about $5-11 \%$ of that of the control at the protein expression level (Fig. 5c) upon pooled siRNA transfection.

Both MCF7 and MDAMB231 cells were subjected to reduced cell viability on SNRPD1 knockdown $(\mathrm{p}=7.56 \mathrm{E}-7$ for MCF7, $\mathrm{p}=1.1 \mathrm{E}-03$ for MDAMD231, Fig. 5d). Significant discrepancies in G1/G2 proportion were observed between the control and si-SNPRD1 cells, suggestive of the important role of SNRPD1 in 'cell cycle'. Cells were arrested at the G1 phase, resulting in $35 \%$ increase of G1 phase cells and $55.7 \%$ decrease of S phase cells, and a slight increase of G2 phase cells were observed in si-SNRPD1 cells (Fig. 6a, b). Similar results were observed in MDAMB361 and HCC1937 cell lines (Fig. 6c, d).

Doxorubicin is one type of anthracycline-like drugs that confers cytotoxicity through its antimitotic activity and thus is effective in killing cells with accelerated cell cycle progression including malignant cells. By applying doxorubicin to SNRPD1-silenced cells, we observed significantly right-ward shifted IC50 in triple negative breast cancer cells MDAMB231 and HCC1937 (Fig. 7b, 7d) but not in luminal cells MCF7 and MDAMB361 (Fig. 7a, c).

There were 92 SRFGs enriched in the cell cycle pathway (HSA-1640170, Additional file 1: Table S4) as predicted using STRING [28]. By classifying these genes into four categories, i.e., 'M' (genes specific to $M$ phase regulation), ' $M$ checkpoint' (genes specific to $M$ phase checkpoint regulation), 'S' (genes specific to $\mathrm{S}$ phase regulation), 'S checkpoint' (genes specific to $\mathrm{S}$ phase checkpoint regulation), we identified $C D C A 5$ as the sole gene specific to $\mathrm{M}$ and $\mathrm{S}$ phase regulation, 30 and 12 genes specific to $M$ and $\mathrm{S}$ phase checkpoint regulation, respectively (Table 3 ). We chose one gene from each of the four categories, i.e., CDCA5 (represents both ' $\mathrm{M}$ ' and ' $\mathrm{S}$ '), NDC80, CCNA2, three genes from G1/S transition (CCNB1, CDK1, PCNA, Table 4) to examine whether these cell cycle related genes could be significantly modulated by SNRPD1 silencing in vitro. All tested genes were significantly altered on SNRPD1 silencing in both MCF7 $(\mathrm{p}=8.2 \mathrm{E}-4$ for $C D C A 5, \mathrm{p}=0.027$ for $N D C 80, \mathrm{p}=6.2 \mathrm{E}-4$ for $C C N A 2$, $\mathrm{p}=0.013$ for $C C N B 1, \mathrm{p}=5.1 \mathrm{E}-4$ for $C D K 1, \mathrm{p}=0.011$ for PCNA, Fig. 8a) and MDAMB231 cells $(\mathrm{p}=3.56 \mathrm{E}-4$ for $C D C A 5, \mathrm{p}=0.0062$ for $N D C 80, \mathrm{p}=2.96 \mathrm{E}-4$ for $C C N A 2$, $\mathrm{p}=0.009$ for $C C N B 1, \mathrm{p}=0.001$ for $C D K 1, \mathrm{p}=0.005$ for PCNA, Fig. 8a).

We, in addition, tested the expression of CCND1 whose down-regulation is associated with $G_{0} / G_{1}$ arrest [29] but missed from the dataset we used for SRFG identification. CCND1 was down-regulated to approximately $20 \%$ and $60 \%$ of the control in SNPRD1-silenced MCF7 and MDAMB231 cells at both gene and protein expression levels $(\mathrm{p}=0.022$ at the gene expression level, $\mathrm{p}=1.53 \mathrm{E}-4$ at the protein expression level in MCF7, $p=0.0023$ at the gene expression level, $\mathrm{p}=1.7 \mathrm{E}-166$ at the protein expression level in MDAMB231, Fig. 8b), suggestive of a $\mathrm{G}_{0} / \mathrm{G}_{1}$ cell cycle arrest.

We next explored whether SNRPD1 directly interacts with cell cycle related genes. By constructing a proteinprotein interaction network of SNRPD1 and the analyzed cell cycle proteins using STRING version 11.0 (https:// string-db.org), we found that SNRPD1 is co-expressed with PCNA with a potential direct interaction (Fig. 8c). We thus conducted immunoprecipitation to assess the interactions of SNPRD1 with PCNA in MCF7 and

(See figure on next page.)

Fig. 4 Assessment of the relationship between SNRPD1 and cell cycle. a Heatmap drawn using cell cycle related genes from SRFGs, and $\mathbf{b}$ GSEA of 'GO_CELL_CYCLE' using the protein_NC dataset. $\mathbf{c}$ Heatmap drawn using cell cycle related genes from SRFGs, and d GSEA of 'BIOCARTA_ CELLCYCLE_PATHWAY' using the gene_TCGA dataset. e Forest plot showing correlations between SNRPD1 and cell cycle related genes from SRFGs across multiple datasets 

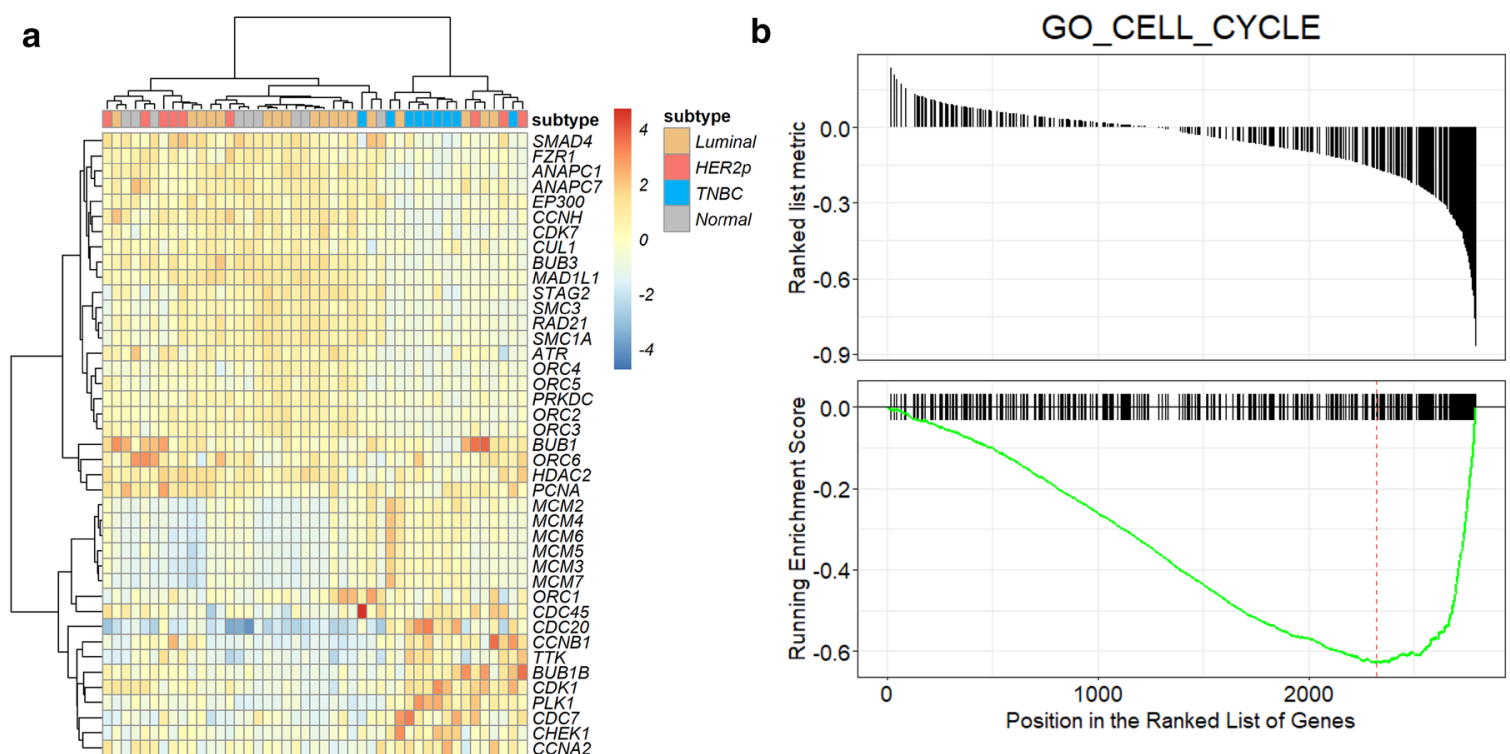

c

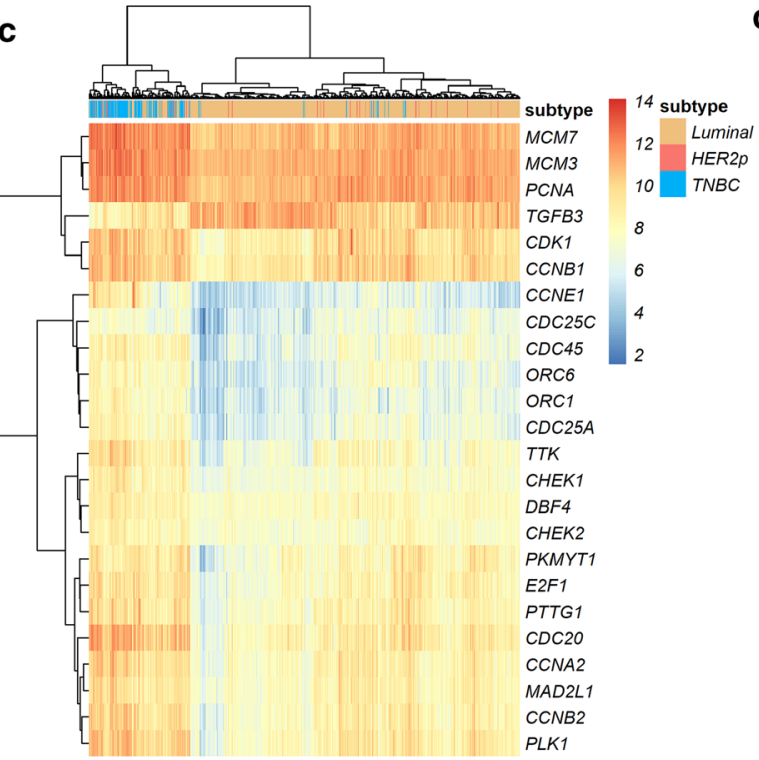

d
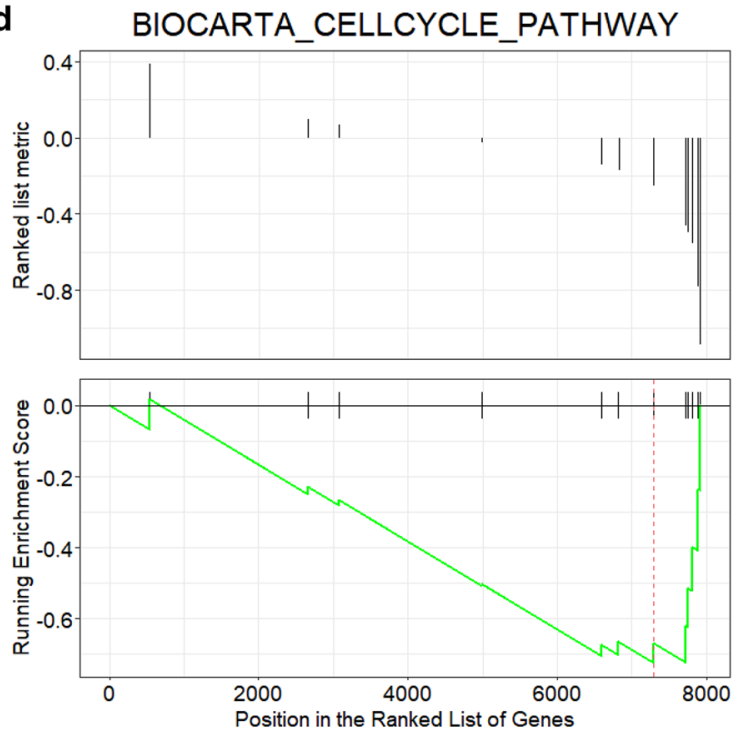

e

\begin{tabular}{lrrrrr|}
\hline & size & lower & median & upper & \\
\hline protein_NC & 45 & 0.1430 & 0.436 & 0.584 & \\
gene_TCGA & 931 & -0.0758 & 0.253 & 0.481 \\
gene_CLM & 56 & 0.1371 & 0.352 & 0.472 & $\substack{0.2 \quad 0.4 \\
\text { pearson correlation }}$ \\
\hline
\end{tabular}




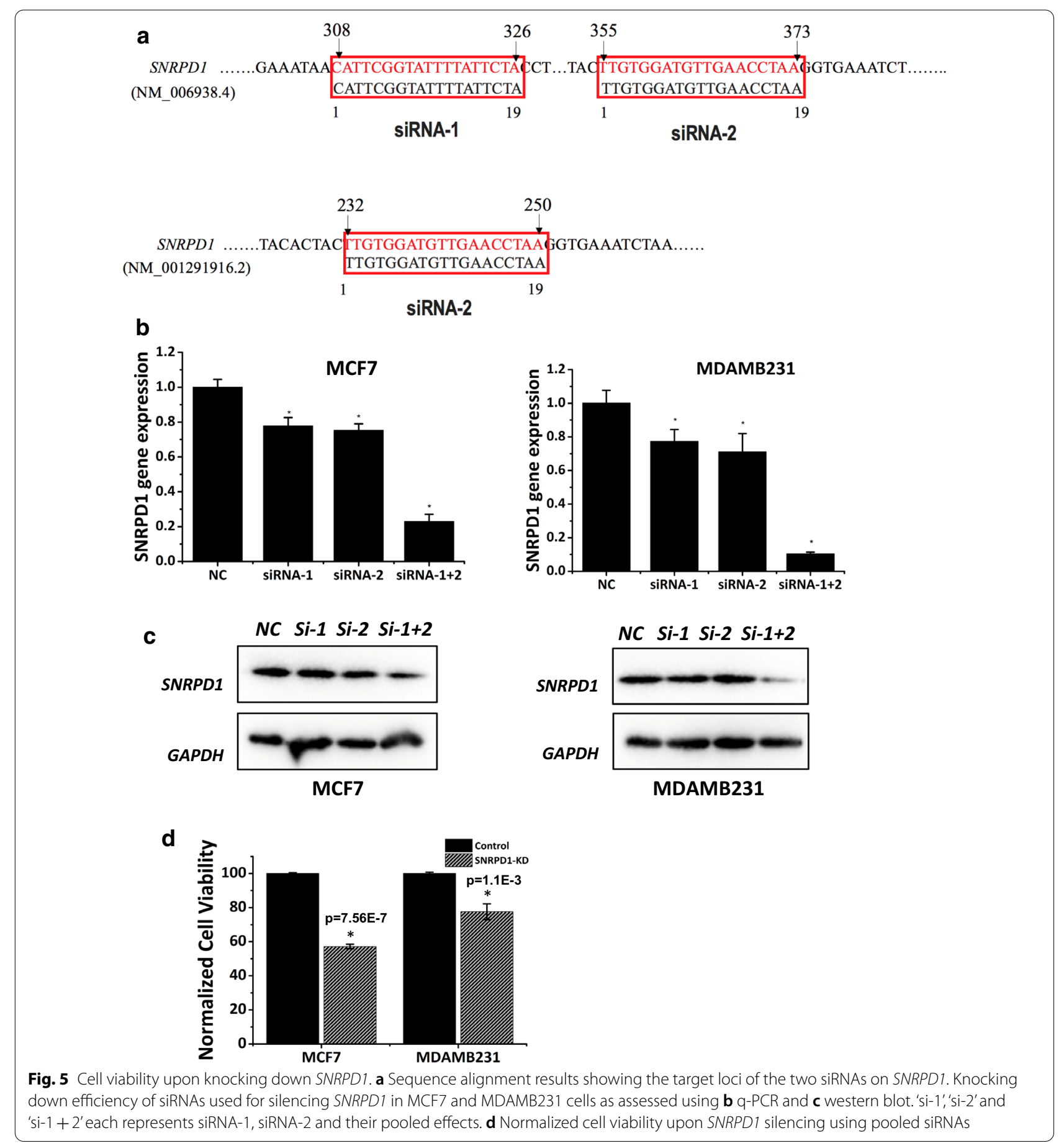

MDAMB231 cells, and the results showed that SNPRD1 physically interacts with PCNA in both cell lines (Fig. 8d).

\section{Discussion}

Through computational predictions followed by experimental validations, we proposed in this study that SNRPD1 over-expression contributes to cell cycle progression whose differential expression is prognostic of breast cancer outcome and associated with breast cancer subtypes, and targeting SNRPD1 could lead to cell cycle arrest at the $\mathrm{G}_{0} / \mathrm{G}_{1}$ stage.

Downward-regulated expression of CDCA5 [30, 31], NDC80 [32], CCNA2 [33] on SNRPD1 silencing suggested reduced synthesis of DNA and proteins as well 
Table 2 Sequence alignment of two designed SNPRD1 siRNA against SNRPD1 and cell cycle related genes experimentally assessed in this study

\begin{tabular}{lllll}
\hline Type & Gene & Accession & Evalue & Significance \\
\hline siRNA-1 & PCNA & NM_182649.2 & 0.18 & \\
& CCND1 & NM_053056.3 & 2.4 & \\
& CCNB1 & NM_031966.4 & 0.29 & \\
& CDK1 & NM_001786.5 & 0.068 & \\
& CDCA5 & NM_080668.4 & 1.4 & \\
& NDC80 & NM_006101.3 & 0.077 & \\
& CCNA2 & NM_001237.5 & 0.39 & \\
& SNRPD1 & NM_006938.4 & $\mathbf{0 . 0 0 0 0 0 0 2}$ & $*$ \\
& SNRPD1 & NM_001291916.2 & 0.16 & \\
siRNA-2 & PCNA & NM_182649.2 & 0.012 & \\
& CCND1 & NM_053056.3 & 0.15 & \\
& CCNB1 & NM_031966.4 & 0.29 & \\
& CDK1 & NM_001786.5 & $/$ & \\
& CDCA5 & NM_080668.4 & 1.4 & \\
& NDC80 & NM_006101.3 & 0.3 & \\
CCNA2 & NM_001237.5 & 0.39 & \\
SNRPD1 & NM_006938.4 & $\mathbf{0 . 0 0 0 0 0 0 2 ~}$ & $*$ \\
SNRPD1 & NM_001291916.2 & $\mathbf{0 . 0 0 0 0 0 0 2 ~}$ & $*$ \\
\hline
\end{tabular}

as recessed cell mitosis. Further evidence on reduced CCND1 expression after knocking down SNRPD1 implicated the accumulation of cells in the $G_{0} / G_{1}$ state given the regulatory role of CCND1 in triggering $G_{0} / G_{1}$ cell cycle arrest [29].

Results from cell flow cytometry showed that reduced SNRPD1 could lead to considerable reduction on the $\mathrm{S}$ phase, supporting the hypothesis that cells are arrested at the $G_{0} / G_{1}$ stage and explaining the mechanism leading to reduced cell viability and increased Anthracycline resistance on knocking down SNRPD1.

It was worth noticing that the role of SNPRD1 in cell cycle arrest is independent of breast cancer subtype though cell cycle related genes could effectively cluster breast cancers into distinct clinically relevant subtypes. This is because that although cell cycle progression is deterministic of cell proliferation, migration and consequently associated with cancer aggressiveness and subtyping, halting cells at a certain cell cycle stage could unanimously block cells from progression regardless of the types of tumor cells.

Being a spliceosomal core Sm protein, SNRPD1 could nicely stratify breast cancer subtypes into TNBCs and non-TNBCs (Fig. 1a), showed comparable sensitivity

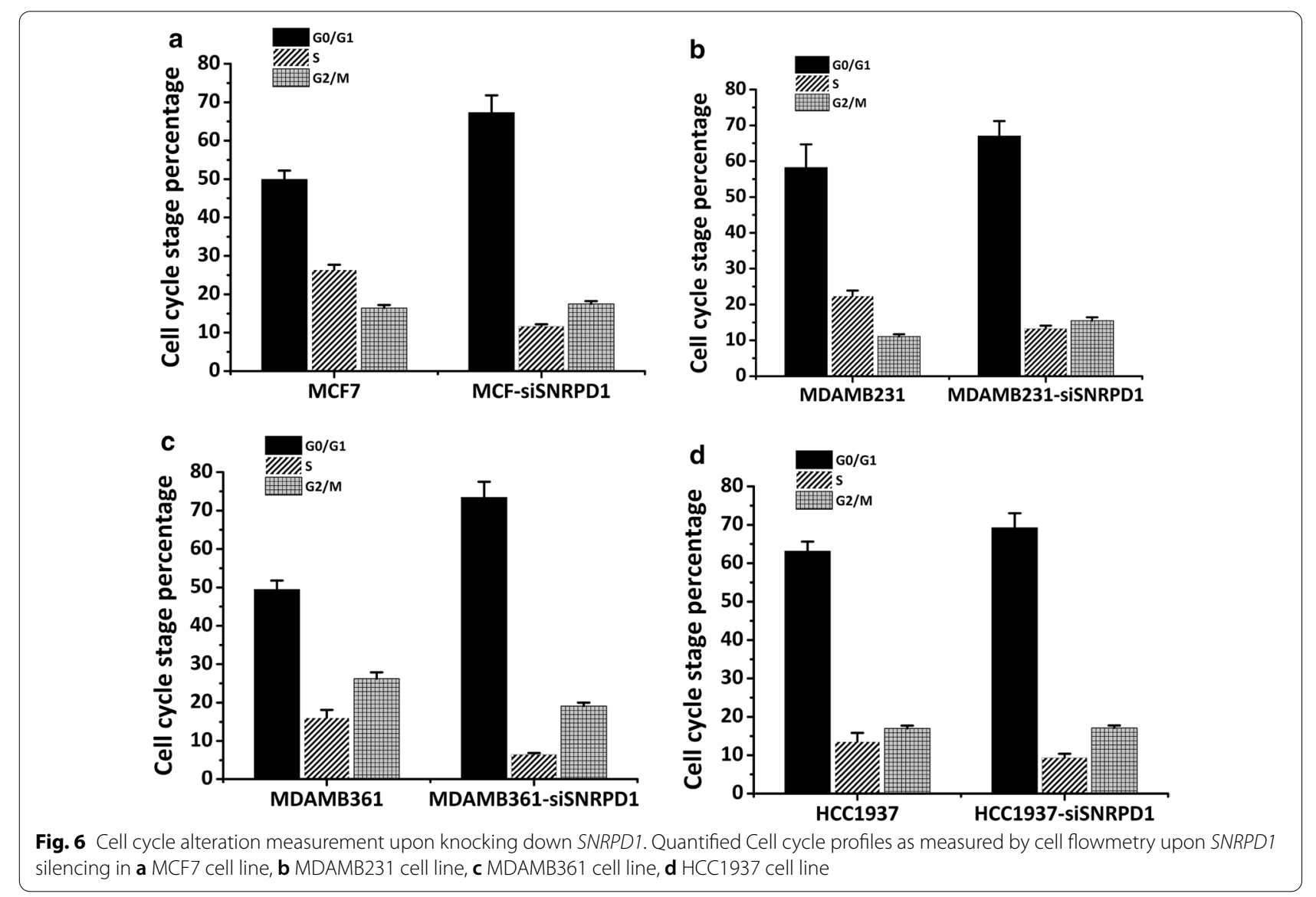



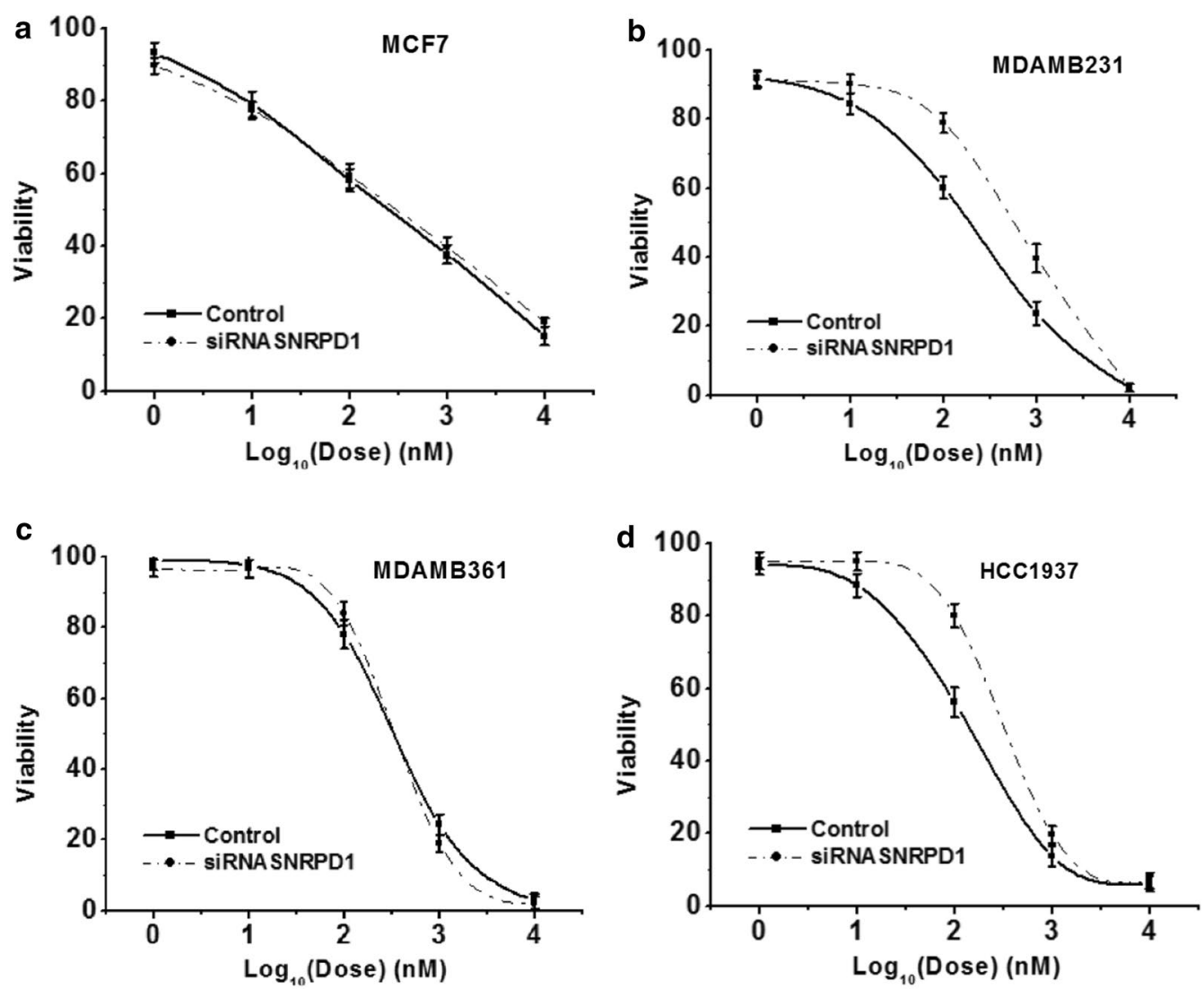

Fig. 7 Cell viability in response to Doxorubicin upon knocking down SNRPD1. Drug response curves with and without silencing SNRPD1 in a MCF7 cell line, b MDAMB231 cell line, c MDAMB361 cell line, d HCC1937 cell line

Table 3 Classification of genes enriched in the cell cycle from Reactome pathways among the 434 SRTNS

\begin{tabular}{|c|c|c|c|c|c|c|c|}
\hline \multicolumn{2}{|l|}{ M } & \multicolumn{2}{|c|}{ M checkpoint } & \multirow{2}{*}{$\begin{array}{l}\text { S } \\
\text { CDCA5 }\end{array}$} & \multirow{2}{*}{$\begin{array}{l}\text { S checkpoint } \\
\text { CCNA2 }\end{array}$} & \multirow{2}{*}{$\frac{\text { Rest }}{\text { BLM }}$} & \multirow{2}{*}{$\frac{\text { Common }}{\text { PSMD3 }}$} \\
\hline AAAS & NCAPG2 & BUB1B & NDC80 & & & & \\
\hline CDCA5 & NCAPH & CCNB1 & NUF2 & CUL1 & $\mathrm{CDC} 45$ & CDC7 & PSMD14 \\
\hline CEP152 & $\mathrm{NCAPH} 2$ & CDC20 & NUP107 & FEN1 & MCM2 & CHEK1 & RPS27A \\
\hline HAUS1 & NDC1 & CDCA8 & NUP133 & PCNA & MCM3 & GMNN & \\
\hline HAUS2 & NUP153 & CDK1 & NUP160 & POLA1 & MCM4 & MCM10 & \\
\hline HAUS3 & NUP155 & CENPF & NUP85 & POLA2 & MCM5 & MDC1 & \\
\hline HAUS4 & NUP205 & CENPH & PLK1 & POLE & MCM6 & MND1 & \\
\hline HAUS5 & NUP210 & CENPI & $\mathrm{RCC2}$ & PRIM1 & MCM7 & TOP3A & \\
\hline HAUS6 & NUP50 & CENPO & SKA1 & PRIM2 & ORC6 & TOPBP1 & \\
\hline HAUS8 & NUP93 & CENPQ & SPC24 & & RFC2 & TPX2 & \\
\hline KIF20A & SMC2 & CENPU & SPC25 & & RFC4 & WHSC1 & \\
\hline MASTL & SMC4 & ERCC6L & XPO1 & & RFC5 & & \\
\hline NCAPD2 & VRK1 & INCENP & ZW10 & & & & \\
\hline NCAPD3 & & $\mathrm{KIF} 2 \mathrm{C}$ & ZWILCH & & & & \\
\hline NCAPG & & KNTC1 & ZWINT & & & & \\
\hline
\end{tabular}

STRING version 11.0 was used to conduct the enrichment analysis. Experimentally tested genes are highlighted in bold face. ' $M$ ' and ' $S$ ' each represents genes specific the $M$ and $S$ phase, respectively. ' $M$ checkpoint' and 'S checkpoint' each means genes specific to $M$ and $S$ phase check point regulation, respectively, which were obtained by taking the intersection of genes between ' $M$ phase' or 'S phase' and 'cell cycle checkpoint' pathways. 'Common' and 'Rest' each represents genes present in and absent from all ' $M$ ', 'M checkpoint', 'S', 'S checkpoint' categories, respectively 
Table 4 Classification of genes enriched in cell cycle transitions from Reactome pathways among the 434 SRTNS

\begin{tabular}{llll}
\hline G1/S transition & \multicolumn{3}{l}{ G2/M transition } \\
\hline CCNA2 & MCM6 & CCNA2 & HAUS8 \\
CCNB1 & MCM7 & CCNB1 & PLK1 \\
CDC45 & ORC6 & CDK1 & PSMD14 \\
CDC7 & PCNA & CENPF & PSMD3 \\
CDK1 & POLA1 & CEP152 & RPS27A \\
CUL1 & POLA2 & CUL1 & TPX2 \\
GMNN & POLE & HAUS1 & XPO1 \\
MCM10 & PRIM1 & HAUS2 & \\
MCM2 & PRIM2 & HAUS3 & \\
MCM3 & PSMD14 & HAUS4 & \\
MCM4 & PSMD3 & HAUS5 & \\
MCM5 & RPS27A & HAUS6 & \\
\hline
\end{tabular}

STRING was used to conduct the enrichment analysis. Experimentally tested genes involved in $\mathrm{G} 1 / \mathrm{S}$ transition are highlighted in bold face

and accuracy with the canonical proliferation marker KI67 in breast cancer subtyping (Fig. 2g), and exhibited similar correlations with KI67 ( $\operatorname{cor}=0.38, p=9.2 \mathrm{E}-33$ ) and the primary breast cancer subtyping marker ER (cor $=-0.39, \mathrm{p}=4.1 \mathrm{E}-36$ ), suggesting the prognostic value of SNRPD1 on breast cancer subtyping and its relevance with cell proliferation.

As doxorubicin is a chemotherapy that is known to target highly proliferative cells and typically used to treat TNBCs (TNBC cells are more sensitive to doxorubicin treatment and have faster cell cycle progression due to their more aggressive nature as compared with luminal cancer cells) in clinics, silencing SNRPD1 would dampen its anti-cancer efficacy if SNRPD1 over-expression was associated with enhanced cell cycle progression. As expected, doxorubicin resistance in response to SNRPD1 silencing was observed in triple negative cell lines but not luminal cells, which complies with our findings on the role of SNRPD1 in cell cycle. Our results also warrant special attention in the combined use of drugs targeting SNRPD1 and anthracycline-like chemotherapies in the treatment of triple negative breast cancers, which needs further in vivo validation.

Abnormal alternative splicing has already been implicated in cancer progression such as cell proliferation, programmed cell death, metabolism, angiogenesis and metastasis [34, 35], rendering splicing an attractive therapeutic target for various types of malignancies[1]. For instance, inhibiting splicing was considered an effective approach to target multiple vulnerabilities of basal A type of TNBCs which reply on RNA splicing for survival [36]. Tumor cells have evolved abilities to hijack the RNA splicing machinery to reprogram gene expression towards their own advantages. It is likely that SNRPD1 over-representation leads to over-expression of genes promoting cell progression and down-regulation of those with cell cycle inhibitory roles due to altered RNA splicing.

We also examined the effect of SNRPD1 on other spliceosome complex proteins using SNRPE as an example. As a result, no visible variation on SNRPE expression was found by silencing SNRPD1 (Additional file 2: Figure S1), suggestive of the independent role of SNRPD1 in breast cancer survival. This does not exclude the possible existence of a cross-talk between SNRPD1 and other ribosome binding proteins such as SF3B1, SF3B2, RPL5, ARCN1, EIF3B, RAN, COPB1, RPL14, VCP, HSPE1, SNRNP200, SARS, EEF2, RPL37, CCT3, KPNB1, RPL23 that have been reported essential for breast cancer survival besides SNRPD1 [14]. However, these are beyond the scope of this paper that focuses on core Sm proteins.

It is worth mentioning that we did not examine the functionalities of SNRPD1 on mRNA splicing which has already been documented [37]. Instead, our focus is laid on the tight association of SNRPD1 with cell cycle to expand our understandings on the multifaceted roles of SNRPD1 and splicing. Splicesome inhibition has been proposed as an effective therapeutic approach for treating MYC-driven breast cancers [38]. Breast cancer cell lines we used in this study include MCF7, MDAMB231, MDAMB361 and HCC1937, which are all not MYC-driven as compared with the quasi-normal cell line MCF10A (Additional file 2: Figure S2). Thus, cell lines we used in this study may not be vulnerable to splicesome inhibitors as to silencing SNRPD1. On the other hand, none of the known splicesome inhibitors (including pladienolide B, E7107, FR901464, meayamycin, spliceostatin A, and sudemycines, isoginkgetin, herboxidine) was reported to target SNRPD1, whereas SF3b was identified as the common target of pladienolides and spliceostatin A $[39,40]$, SAP155 was that of herboxidine [41], and MMP9 was that of isoginkgetin [42]. Thus, splicesome inhibitors, though modulating the splicing process, may not affect SNRPD1 expression and thus achieve

\footnotetext{
(See figure on next page.)

Fig. 8 Expression of cell cycle related genes and potential mechanism of SNRPD1 in cell cycle regulation. a Expression of cell cycle related genes CDCA5, NDC80, CCNA2, PCNA, CCNB1, CDK1, CCND1 after silencing SNRPD1 at the mRNA level in MCF7 and MDAMB231 cells. b Expression of cell cycle related gene CCND1 after silencing SNRPD1 at the (b) proteomic levels together with its quantified signal intensity in MCF7 and MDAMB231 cells. c Predicted protein-protein interaction network of SNRPD1 and cell cycle related proteins using STRING. $\mathbf{d}$ Immunoprecipitation of SNRPD1 and PCNA in MCF7 and MDAMB231 cells
} 
a

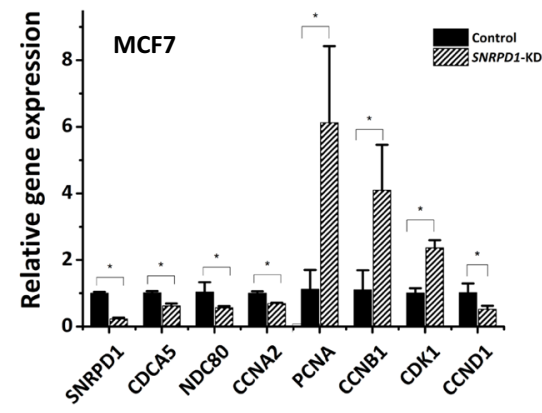

b

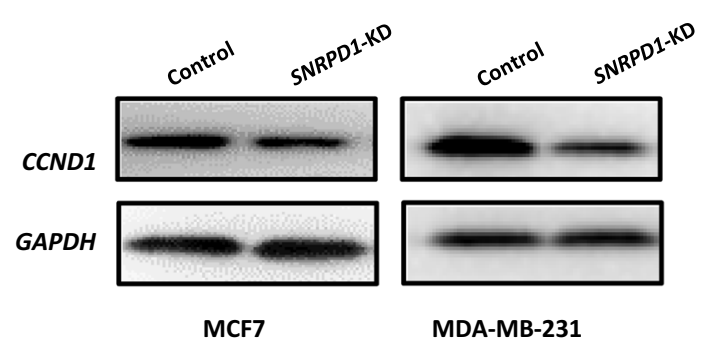

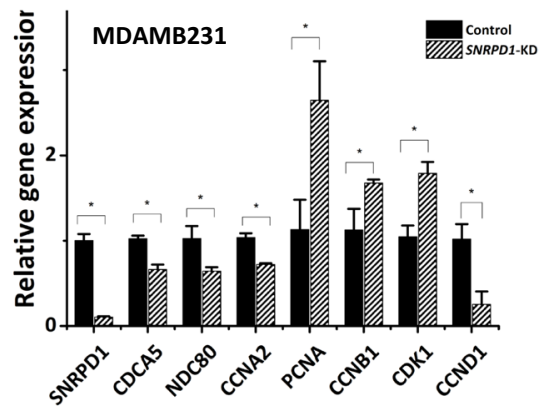

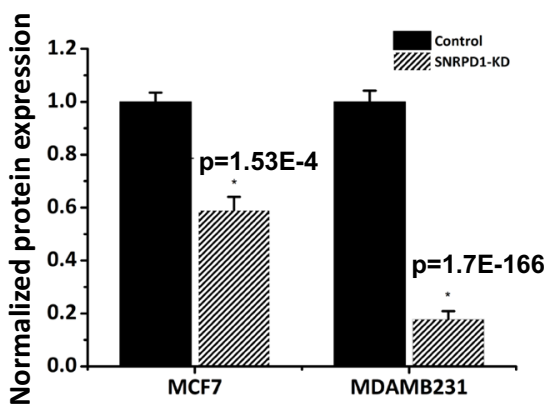

c

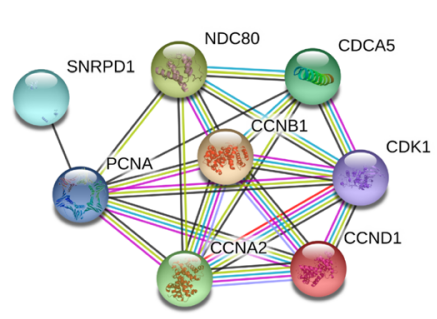

d

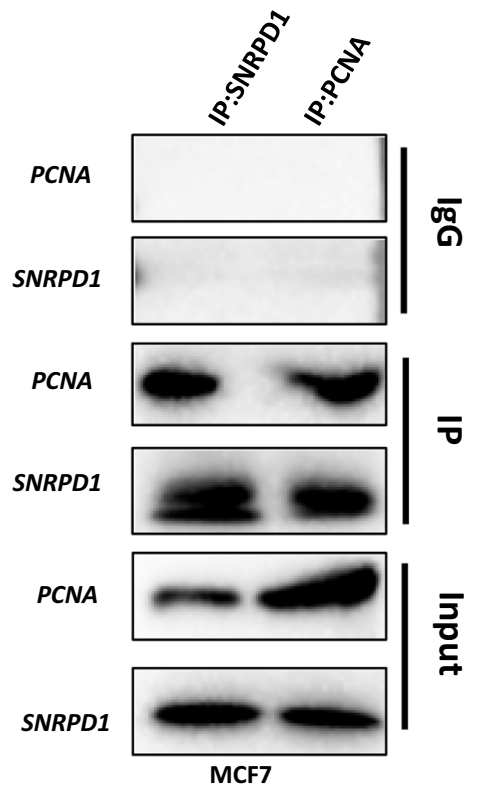

Known interactions

From curated databases

Experimentally determined

Predicted interactions

Co-expression

Protein homology

Gene neighborhood

Gene fusions

Gene co-occurrence

\section{Others}

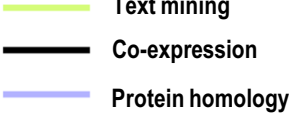

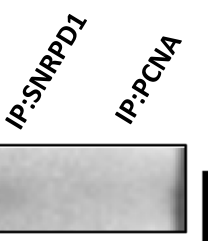

PCNA
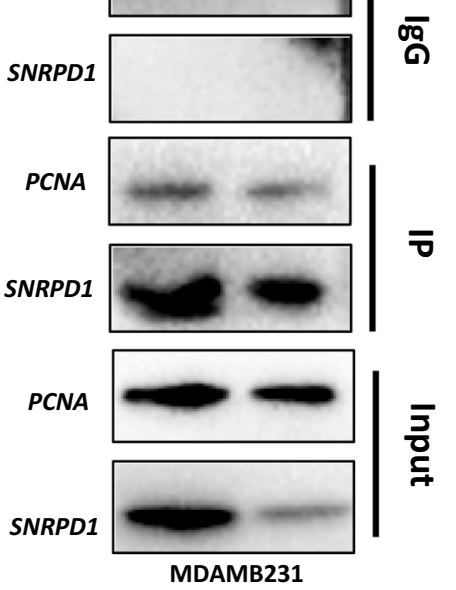
similar effects. As one evidence here, silencing SNRPD1 did not affect the VEGF/VEGFR axis (Additional file 2: Figure S3) that was reported to be modulated by spliceostatin A [43]. In addition, due to cytotoxicity, spliceosome inhibitors may cause cell cycle alterations under appropriate dosing [44] which, however, is not through targeting SNRPD1.

\section{Conclusions}

We identified the novel association of SNRPD1 with cell cycle progression in breast cancers, and therefore proposed SNRPD1 as a novel target for breast cancer control through halting cell cycle progression at the $G_{0} / G_{1}$ phase. We are the first to link the role of SNRPD1 with cell cycle progression and explain the distinct clinical outcomes of breast cancer subtypes using its differential expression. This study implicates the therapeutic potential of SNRPD1 in breast cancer control that might be expanded to other types of cancers and warrants the combined use of doxorubicin and drugs targeting SNRPD1 in treating triple negative breast cancers, which are subjected to experimental validations.

\section{Supplementary Information}

The online version contains supplementary material available at https://doi. org/10.1186/s12935-021-01932-w.

Additional file 1: Table S1. Information on siRNAs purchased for knocking down SNRPD1 in the study. Table S2. Information on the qPCR primers used in the experiment. Table S3. Information of 434 SRTNS from data analysis using protein MS data. Table S. Key cell cycle related Reactome pathways enriched by 434 SRTNS. The prediction was conducted using STRING. Table S5. Expansion of abbreviations in Fig. 2a.

Additional file 2: Figure S1. SNRPE protein expression in MCF7 and MDAMB231 cells on SNRPD1 silencing. Figure S2. MYC gene expression in different breast cancer cell lines and quasi-normal breast cancer cells from (A) GSE12790 and (B) E-MTAB-181 datasets. MCF10A was the quasi-normal breast cancer cell line. The GSE12790 dataset [45, 46] and E-MTAB-181 [20] dataset were retrieved from GEO and ArrayExpress, respectively. The data was normalized using the robust multichip average (RMA) approach from the R package 'affy'. Figure S3. VEGFR2 protein expression in MCF7 and MDAMB231 cells on SNRPD1 silencing.

\section{Acknowledgements}

Not applicable.

\section{Authors' contributions}

XD designed, supervised this study and drafted the manuscript. XD and XC conducted the bioinformatics analysis, LY carried out the experiments. XD prepared the tables. LY, XC and XD prepared the figures. XD and JZ financed this study. All authors read and approved the final manuscript.

\section{Funding}

This study was funded by the National Natural Science Foundation of China (Grant No. 81972789), Fundamental Research Funds for the Central Universities (Grant No. JUSRP22011), Technology Development Funding of Wuxi (Grant No. WX18IVJN017). These funding sources have no role in the study design, data collection and analysis, decision to publish, or preparation of the manuscript.

Availability of data and materials

All data used are publicly available.

\section{Declarations}

Ethics approval and consent to participate

Not applicable.

\section{Consent for publication}

All authors are consent for the publication of this work.

\section{Competing interests}

All authors declare no competing interest.

\section{Author details}

${ }^{1}$ Wuxi School of Medicine, Jiangnan University, Wuxi, Jiangsu, China. ${ }^{2}$ School of Biotechnology, Jiangnan University, Wuxi, Jiangsu, China. ${ }^{3}$ Henan Academy of Medical and Pharmaceutical Sciences, Zhengzhou University, Zhengzhou, Henan, China.

Received: 7 November 2020 Accepted: 13 April 2021

Published online: 20 April 2021

\section{References}

1. Bonnal S, Vigevani L, Valcarcel J. The spliceosome as a target of novel antitumour drugs. Nat Rev. 2012;11:847-57.

2. Papasaikas $P$, Valcarcel J. The spliceosome: the ultimate RNA chaperone and sculptor. Trends Biochem Sci. 2016;41(1):33-45.

3. Dutertre M, Vagner S, Auboeuf D. Alternative splicing and breast cancer. RNA Biol. 2010;7(4):403-11.

4. Fackenthal JD, Godley LA. Aberrant RNA splicing and its functional consequences in cancer cells. Dis Model Mech. 2008;1(1):37-42.

5. Pajares MJ, et al. Alternative splicing: an emerging topic in molecular and clinical oncology. Lancet Oncol. 2007;8(4):349-57.

6. Skotheim RI, Nees M. Alternative splicing in cancer: noise, functional, or systematic? Int J Biochem Cell Biol. 2007;39(7-8):1432-49.

7. Venables JP. Unbalanced alternative splicing and its significance in cancer. BioEssays. 2006;28(4):378-86.

8. Kalnina Z, et al. Alterations of pre-mRNA splicing in cancer. Genes Chromosomes Cancer. 2005:42(4):342-57.

9. Wang $L$, et al. SF3B1 and other novel cancer genes in chronic lymphocytic leukemia. N Engl J Med. 2011;365(26):2497-506.

10. Graubert TA, et al. Recurrent mutations in the U2AF1 splicing factor in myelodysplastic syndromes. Nat Genet. 2011;44(1):53-7.

11. Quesada V, et al. Exome sequencing identifies recurrent mutations of the splicing factor SF3B1 gene in chronic lymphocytic leukemia. Nat Genet. 2011:44(1):47-52.

12. Yoshida $\mathrm{K}$, et al. Frequent pathway mutations of splicing machinery in myelodysplasia. Nature. 2011;478(7367):64-9.

13. Andre $F$, et al. Exonic expression profiling of breast cancer and benign lesions: a retrospective analysis. Lancet Oncol. 2009;10(4):381-90.

14. Santiago Guerrero, et al., In silico analyses reveal new putative 1 Breast Cancer RNA-binding proteins. Biorxiv, 2020: p. preprint.

15. Quidville V, et al. Targeting the deregulated spliceosome core machinery in cancer cells triggers mTOR blockade and autophagy. Cancer Res. 2013;73(7):2247-58.

16. Johansson $\mathrm{HJ}$, et al. Breast cancer quantitative proteome and proteogenomic landscape. Nat Commun. 2019;10(1):1600.

17. The Cancer Genome Atlas (TCGA). Available from: https://tcga-data.nci. nih.gov/tcga/.

18. Tang Z, et al. GEPIA: a web server for cancer and normal gene expression profiling and interactive analyses. Nucleic Acids Res. 2017;45(W1):W98-102.

19. Heiser LM, et al. Subtype and pathway specific responses to anticancer compounds in breast cancer. Proc Natl Acad Sci USA. 2012;109(8):2724-9.

20. Shen $\mathrm{L}$, et al. Metabolic reprogramming in triple-negative breast cancer through Myc suppression of TXNIP. Proc Natl Acad Sci USA. 2015;112(17):5425-30.

21. Gyorffy B, et al. An online survival analysis tool to rapidly assess the effect of 22,277 genes on breast cancer prognosis using microarray data of 1,809 patients. Breast Cancer Res Treat. 2010;123(3):725-31. 
22. The Gene Ontology(GO). http://www.geneontology.org.

23. Kyoto Encyclopedia of Genes and Genomes database (KEGG). http:// www.genome.jp/kegg/pathway.html.

24. Yu G, et al. clusterProfiler: an R package for comparing biological themes among gene clusters. OMICS. 2012;16(5):284-7.

25. Wang Y, et al. Identification of methylated genes and miRNA signatures in nasopharyngeal carcinoma by bioinformatics analysis. Mol Med Rep. 2018;17(4):4909-16.

26. Frommolt P, Thomas RK. Standardized high-throughput evaluation of cell-based compound screens. BMC Bioinform. 2008;9:475.

27. Denkert C, et al. Molecular alterations in triple-negative breast cancer-the road to new treatment strategies. Lancet. 2017;389(10087):2430-42.

28. Szklarczyk D, et al. STRING v11: protein-protein association networks with increased coverage, supporting functional discovery in genome-wide experimental datasets. Nucleic Acids Res. 2019;47(D1):D607-13.

29. Zhang $L$, et al. NFE2L3 inhibition induces cell cycle arrest at the G0/G1 phase in colorectal cancer cells through downregulating CCND1 and pRb1-ser807/811. Dis Markers. 2019;2019:2829798.

30. Fu G, et al. CDCA5 functions as a tumor promoter in bladder cancer by dysregulating mitochondria-mediated apoptosis, cell cycle regulation and PI3K/AKT/mTOR pathway activation. J Cancer. 2020;11(9):2408-20.

31. Bai L, Ren Y, Cui T. Overexpression of CDCA5, KIF4A, TPX2, and FOXM1 coregulated cell cycle and promoted hepatocellular carcinoma development. J Comput Biol. 2019;27(6):965-74.

32. Sun SC, et al. Ndc80 regulates meiotic spindle organization, chromosome alignment, and cell cycle progression in mouse oocytes. Microsc Microanal. 2011;17(3):431-9.

33. Yang $\mathrm{R}$, et al. Weighted gene co-expression network analysis identifies CCNA2 as a treatment target of prostate cancer through inhibiting cell cycle. J Cancer. 2020;11(5):1203-11.

34. David CJ, Manley JL. Alternative pre-mRNA splicing regulation in cancer: pathways and programs unhinged. Genes Dev. 2010;24(21):2343-64.

35. Kaida D, Schneider-Poetsch T, Yoshida M. Splicing in oncogenesis and tumor suppression. Cancer Sci. 2012;103(9):1611-6.
36. Chan S, et al. Basal-A triple-negative breast cancer cells selectively rely on RNA splicing for survival. Mol Cancer Ther. 2017;16(12):2849-61.

37. Kim YD, et al. The unique spliceosome signature of human pluripotent stem cells is mediated by SNRPA1, SNRPD1, and PNN. Stem Cell Res. 2017;22:43-53.

38. Hsu TY, et al. The spliceosome is a therapeutic vulnerability in MYC-driven cancer. Nature. 2015;525(7569):384-8.

39. Kotake $Y$, et al. Splicing factor SF3b as a target of the antitumor natural product pladienolide. Nat Chem Biol. 2007;3(9):570-5.

40. Kaida D, et al. Spliceostatin A targets SF3b and inhibits both splicing and nuclear retention of pre-mRNA. Nat Chem Biol. 2007;3(9):576-83.

41. Hasegawa M, et al. Identification of SAP155 as the target of GEX1A (Herboxidiene), an antitumor natural product. ACS Chem Biol. 2011;6(3):229-33.

42. Yoon SO, et al. Isoginkgetin inhibits tumor cell invasion by regulating phosphatidylinositol 3-kinase/Akt-dependent matrix metalloproteinase-9 expression. Mol Cancer Ther. 2006;5(11):2666-75.

43. Furumai $R$, et al. Spliceostatin A blocks angiogenesis by inhibiting global gene expression including VEGF. Cancer Sci. 2010;101(11):2483-9.

44. Vanzyl EJ, et al. Flow cytometric analysis identifies changes in S and M phases as novel cell cycle alterations induced by the splicing inhibitor isoginkgetin. PLoS ONE. 2018;13(1):e0191178.

45. Stinson $\mathrm{S}$, et al. TRPS1 targeting by miR-221/222 promotes the epithelialto-mesenchymal transition in breast cancer. Sci Signal. 2011;4(177):ra41.

46. Hoeflich KP, et al. In vivo antitumor activity of MEK and phosphatidylinositol 3-kinase inhibitors in basal-like breast cancer models. Clin Cancer Res. 2009:15(14):4649-64.

\section{Publisher's Note}

Springer Nature remains neutral with regard to jurisdictional claims in published maps and institutional affiliations.
Ready to submit your research? Choose BMC and benefit from:

- fast, convenient online submission

- thorough peer review by experienced researchers in your field

- rapid publication on acceptance

- support for research data, including large and complex data types

- gold Open Access which fosters wider collaboration and increased citations

- maximum visibility for your research: over 100M website views per year

At BMC, research is always in progress.

Learn more biomedcentral.com/submissions 